\title{
IMPLICAÇÕES DO PROCESSO PRODUTIVO NA QUALIDADE DO QUEIJO ARTESANAL SERRANO
}

\author{
Implications of the quality of the production process artisan cheese serrano \\ Bianca Pinto Pereira', Tatiana Regina Vieira ${ }^{2}$, Joice Zagna Valent ${ }^{3}$, Adriano Bruzza ${ }^{4}$, Saionara Araújo Wagner ${ }^{5}$, \\ Andrea Troller Pinto ${ }^{5}$, Verônica Schmidt ${ }^{5}$ \\ 'Médica Veterinária, Secretaria de Agricultura do município de Cambará do Sul, RS; \\ ${ }^{2}$ Graduanda da Faculdade de Veterinária, Universidade Federal do Rio Grande do Sul, Bolsista de Iniciação Científica CNPq- UFRGS; \\ ${ }^{3}$ Programa de Pós-graduação em Agronegócios, UFRGS; \\ ${ }^{4}$ Programa de Pós-graduação em Ciências Veterinárias - UFRGS; \\ ${ }^{5}$ Faculdade de Veterinária, Universidade Federal do Rio Grande do Sul
}

\begin{abstract}
Resumo
O Queijo Artesanal Serrano (QAS) é um produto fabricado nos campos de altitude no sul do Brasil, na região compreendida pelos Campos de Cima da Serra. Originalmente, este era um produto excedente, trocado pelos tropeiros por produtos em outras regiões. Atualmente, o queijo pode ser responsável por até $60 \%$ da renda das propriedades. O QAS é produzido com leite cru, proveniente de raças bovinas de corte na própria propriedade. Assim, realizou-se um estudo descritivo de revisão bibliográfica com o objetivo de descrever o processo produtivo do Queijo Artesanal Serrano e relacioná-lo à qualidade do produto e à segurança alimentar. Considerando a elaboração de um regulamento técnico próprio à produção do QAS, algumas propriedades têm investido na construção de ambientes apropriados para sua produção, visando à qualidade e inocuidade do queijo produzido. A implantação de Boas Práticas Agropecuárias já demonstrou melhora significativa na qualidade do leite utilizado na produção do QAS e está em fase de estudo a implantação de Boas Práticas de Fabricação nas propriedades produtoras.
\end{abstract}

Palavras-chave: queijo, qualidade, produção artesanal.

\begin{abstract}
The Serrano Handmade Cheese (SHC) is a product manufactured on high altitude fields in southernmost Brazil. This region is formed by northeastern Rio Grande do Sul and Santa Catarina Southern Plateau. Originally, this was a overplus good exchanged for another goods by drovers of this region. Currently, the SHC may be responsible for up to $60 \%$ of properties income. The SHC is produced with raw milk from cattle ranching within the property. Thus, was performed a descriptive study of literature review aiming to describe the production process of Serrano Handmade Cheese. A look on product quality and food safety theoretical contribuiton was sought also. Considering the technical regulation development to SHC some properties has build appropriate production environments. Those actions are aiming quality and safety of the cheese made. The implementation of Good Agricultural Practice has shown significant quality improvement of the milk used to produce this cheese. The implementation of Good Manufacturing Practice is under study in these producing properties.
\end{abstract}

Key words: cheese, quality, handmade production 


\section{INTRODUÇÃO}

O Queijo Artesanal Serrano (QAS) é um produto fabricado nos campos de altitude, acima de $1.000 \mathrm{~m}$ do nível do mar, do sul do Brasil, na região compreendida pelos Campos de Cima da Serra, no nordeste do Rio Grande do Sul (14 cidades) e pelo Planalto Sul Catarinense (18 cidades). É uma área de transição entre o Bioma Pampa e a Mata Atlântica, com invernos rigorosos, sendo a pecuária extensiva em campo nativo a principal atividade econômica (AMBROSINI, 2007; CRUZ et al., 2008).

A colonização dos Campos de Cima da Serra iniciou-se com imigrantes portugueses, mais tarde, em menor quantidade, por imigrantes de origem alemã e italiana. Era rota comercial dos tropeiros que levavam produtos da Região Sul para serem vendidos na Região Sudeste. Sua ocupação baseou-se na doação de terras e formação de grandes propriedades latifundiárias, com objetivo de ocupação do território e o aproveitamento da imensa reserva de animais deixada pelos padres jesuítas, com o fim das reduções no Rio Grande do Sul, durante o século XVIII (CRUZ et al., 2008).

A produção de QAS teve início, juntamente, com a ocupação dos primeiros colonizadores. Originalmente, era um produto excedente, juntamente com o couro e pinhão, que era trocado pelos tropeiros por sal, açúcar, tecido, cachaça, entre outros, em outras regiões. Atualmente, o queijo pode ser responsável por 10 a $60 \%$ da renda das propriedades. Por não ser sazonal, é utilizado para custear despesas diárias da casa, ao contrário da venda de gado que é sazonal e sua receita é utilizada para custear despesas da propriedade, auxiliando a manutenção da família no campo, mantendo suas atividades pecuárias e preservando características socioculturais da região (AMBROSINI, 2007; AMBROSINI; FILIPPI, 2008).

O queijo é produzido, conforme a tradição histórica e cultural da região, a partir do leite cru integral de vacas de raças de corte, obtido e beneficiado na propriedade de origem, e que apresente consistência firme, cor e sabor próprios, massa uniforme, isenta de corantes e conservantes, com ou sem olhaduras mecânicas.

A produção do QAS segue a linha de alimentos slow food, a qual presa pela manutenção da cultura dos povos, sustentabilidade e incentivo aos pequenos produtores. Mesmo dentro desses preceitos, alimentos produzidos em todo o território nacional devem seguir normas estipuladas pelos órgãos de saúde e vigilância sanitária, a fim de garantir a segurança alimentar da população. Neste contexto, as unidades produtoras vêm buscando adequação de seus produtos. Em 2010, a Secretaria de Agricultura, Pecuária e Agronegócio do estado do Rio Grande do Sul aprovou o Regulamento Técnico Para Fixação de Identidade e Qualidade do Queijo Artesanal Serrano e seu processo de fabricação (RIO GRANDE DO SUL, 2010).

O presente artigo tem por objetivo descrever o processo produtivo do Queijo Artesanal Serrano e a implicação deste processo com a qualidade deste produto e a segurança alimentar.

\section{MATERIAL E MÉTODOS}

Este é um estudo do tipo descritivo, pois apresenta como objetivo a descrição das características de determinado processo produtivo. A natureza dos dados é objetiva, porque se baseou em dados já descritos e, pela extensão de seu campo, tratou-se de um levantamento. A análise de tratamento dos dados foi qualitativa (CERVO; BERVIAN, 1983), porque no presente trabalho analisaram-se diversas publicações científicas para descrever o assunto pesquisado, permitindo a inferência de conhecimentos relativos às produções (BARDIN, 2011).

A fonte de coleta de dados foi secundária, porque este trabalho consiste em uma pesquisa bibliográfica, constituída pela análise de fontes publicadas acerca de determinado tema (GIL, 2008). No presente estudo foram pesquisados assuntos relativos ao processo produtivo do QAS e dos fatores que contribuem ou interferem na qualidade deste produto. A pesquisa bibliográfica é o levantamento de um determinado tema, processado em bases de dados nacionais e internacionais, que contêm artigos de revistas, livros, teses e outros documentos. GIL (2008) complementa afirmando que este tipo de pesquisa se propõe à análise de diversas posições sobre um problema.

\section{REVISÃO DE LITERATURA}

Apresentam-se, a seguir, características das unidades produtivas de leite nos Campos de Cima da Serra e do processo de fabricação do queijo Artesanal Serrano, relacionando-as às questões de segurança alimentar. 


\section{A UNIDADE PRODUTIVA DO LEITE}

Nas propriedades produtoras de QAS, a mão-de-obra é quase que exclusivamente familiar, sendo responsabilidade masculina o manejo com os animais e feminina a ordenha juntamente à produção do queijo. A produção do leite para elaboração do QAS é proveniente de raças de corte ou mestiças, com grande influência das zebuínas, como Gir e Guzerá (PEREIRA, 2010).

No sistema de produção difundido na região, os terneiros passam o dia com as vacas, sendo separados no final da tarde. No início da manhã, estes são trazidos para junto das vacas, no momento da ordenha, para estimular a descida do leite através do apojo, que significa deixar os terneiros sugar o primeiro leite da ordenha matinal, afim de que o leite flua mais facilmente (KRONE, 2009).

A preparação do úbere e estímulo da descida do leite a partir da mamada pelo bezerro (apojo) pode contribuir para a contaminação das tetas e dificultar os procedimentos higiênicos da ordenha. Brito et al. (2000) observaram que a mamada para estimular a descida do leite contribuiu para aumentar em mais de 10 vezes o número de microrganismos da superfície das tetas. A higienização das tetas antes da ordenha, procedimento que vem sendo estimulado nas unidades produtivas de QAS, contribui para melhorar a qualidade do leite e para prevenir e controlar as infecções da glândula mamária (PANKEY, 1989), já que reduzem o risco de contaminações e limitam a colonização do leite por microrganismos oriundos da própria pele e ambiente (CARNEIRO FILHA et al., 2009). Os cuidados higiênicos recomendados para o período da ordenha baseiam-se em estudos e procedimentos que contemplam o manejo e os equipamentos da ordenha mecanizada.

Várias práticas de preparação do úbere são utilizadas antes da ordenha, que vão desde o estímulo com o bezerro sem prévia higienização, até a higienização e secagem (PANKEY, 1989). A legislação brasileira (BRASIL, 2011) prevê que as tetas do animal a ser ordenhado devam sofrer prévia lavagem com água corrente, seguindo-se de secagem com toalhas descartáveis de papel não reciclado e início imediato da ordenha, com descarte dos jatos iniciais de leite em caneca de fundo escuro ou em outro recipiente específico para essa finalidade.

O leite é considerado um produto importante na alimentação humana por ser fonte de proteínas, gorduras, energia e sais minerais. Porém, os mesmos constituintes que o fazem um produto bom para o consumo humano o tornam um excelente substrato para o desenvolvimento de microrganismos que podem deteriorá-lo ou, até mesmo, trazer prejuízos à saúde da população.

Os critérios indicativos da qualidade higiênica do leite cru incluem baixo número de microrganismos saprófitos ou patogênicos, os quais podem ter origem no interior da glândula mamária (nos casos de infecções, como mastite), no exterior do úbere e das tetas (microbiota da pele ou contaminações) e nos equipamentos de ordenha e de armazenamento do leite (higienização ou sanitização ineficiente).

Terminada a ordenha, os terneiros acompanham as vacas para o pasto até o entardecer, quando são novamente separados, até o aparte definitivo ou desmame, que ocorre aos seis meses de idade (PEREIRA, 2010).

Embora em algumas propriedades as vacas ordenhadas possam receber suplementação ou ter acesso a pequenas áreas de pastagem cultivada de inverno, na maioria destas a alimentação é baseada nos campos nativos (RIES et al., 2012). A disponibilidade de forrageiras dos campos nativos concentra a produção de queijo nos períodos de primavera/verão, onde está a maior disponibilidade de alimentos e maior produção de terneiros (KRONE; MENASCHE, 2007). Neste período, a temperatura ambiente torna-se um fator importante na questão de conservação do produto, uma vez que em parte dos produtores não existe local específico para maturação do queijo.

Em estudos realizados na região dos Campos de Cima da Serra, verificou-se que as unidades produtivas possuem área de 10 a 220 hectares e rebanhos com 15 a 204 animais, sendo de três a 28 em lactação (SCHNEIDER, 2009; PEREIRA, 2010). Nenhuma propriedade possuía plano de gerenciamento, ou registro das atividades da propriedade, e nem controle dos insumos utilizados, ou da quantidade de queijo produzida, sendo o registro do número de animais realizado compulsoriamente na Inspetoria Veterinária local. Entretanto, os animais não possuíam registros de movimentação e nascimentos, assim como nenhuma identificação como brincos ou sistema de rastreamento. Os animais não eram separados por idade ou sexo, permanecendo juntos de acordo com o espaço permitido na lotação dos piquetes. Desta forma, os touros permanecem junto às fêmeas por todo o ano, não sendo estabelecido um período para cobertura e parição. 


\section{O PROCESSO PRODUTIVO DO QUEIJO}

A produção do QAS ocorre na própria propriedade e a queijaria localiza-se em peça anexa ao galpão ou à moradia. Entretanto, com a elaboração de regulamento técnico próprio à produção do QAS, algumas propriedades têm investido na construção de ambientes apropriados para a produção do produto, visando à qualidade e inocuidade do queijo produzido.

Tradicionalmente, o processo de trabalho na fabricação do queijo tem início na tarde do dia anterior à produção do queijo, quando se recolhe o gado e são apartados os terneiros das vacas (KRONE; MENASCHE, 2007). O queijo é feito logo após a ordenha, sua receita tem, aproximadamente, duzentos anos e vem sendo passada, verbalmente, de geração a geração, sendo fruto de herança familiar e da cultura regional. A falta de padronização do QAS se deve, entre outros fatores, à ausência de processo térmico durante a produção do mesmo (AMBROSINI, 2007; CRUZ et al., 2008).

O tratamento térmico pode ser aplicado em nível doméstico ou industrial e, além de modificar física e quimicamente os alimentos melhorando o sabor, cheiro, aparência e digestibilidade, podem reduzir os níveis de contaminação microbiana, tornando os alimentos seguros para o consumo, uma vez que a maioria das bactérias patogênicas é mesófila (bactérias que apresentam seu crescimento ótimo entre 30 e $45^{\circ} \mathrm{C}$ ) e são destruídas pelo tratamento térmico, além de prolongar o tempo de vida de prateleira (FORSYTHE, 2013; MORAES, 2005).

No caso do leite, o processo térmico utilizado, geralmente, é a pasteurização, que foi instituída no Brasil, por questões de Saúde Pública, antes do estabelecimento de programas sanitários de controle e erradicação de enfermidades nos animais de produção. A pasteurização tem como vantagem tecnológica a diminuição das fermentações anormais e, com isto, maior rendimento e melhor textura dos produtos derivados do leite bovino.

No processamento do leite, tanto na forma artesanal quanto industrial, se este for realizado sem o devido controle higiênico-sanitário, poderá ocorrer contagem elevada de microrganismos, tanto deteriorantes quanto patogênicos, que encontram condições propícias para seu desenvolvimento.

A produção do QAS é constituída por seis etapas (filtragem do leite, adição do coalho, corte da coalhada e amassamento, enformagem, pren- sagem e maturação), descritas a seguir.

\section{I Filtragem}

Após a ordenha, o leite é filtrado com a finalidade de remover material estranho ao leite. A recomendação de boas práticas agropecuárias (BPA) é que esta etapa seja realizada em filtros de inox ou plástico. Entretanto, na maioria das propriedades, o leite é coado em tecido branco. Também Pedrico et al. (2009), em propriedades leiteiras em um assentamento de reforma agrária, verificaram que a filtragem do leite era realizada com pano. A utilização do pano não é adequada pois este, além de utilizado diariamente, pode ser um meio de contaminação do leite.

No processo de produção do QAS, o leite é filtrado e acrescenta-se o coalho (e em algumas propriedades acrescenta-se também o sal).

$\mathrm{Na}$ produção de QAS, além da adição parcial do sal sobre o coador no momento da filtragem do leite, a salga pode ser realizada com a colocação de sal diretamente na massa ou através de salmoura (RIES et al., 2012). A salga é um passo essencial na produção de queijo. $\mathrm{O}$ sal $(\mathrm{NaCl})$ é utilizado como conservante alimentar no queijo por contribuir para o controle do crescimento e atividade microbiana, mediante o decréscimo da atividade da água que conduz à minimização da esporulação e prevenção do desenvolvimento de patogénicos no alimento.

\subsection{Adição de coalho}

Para se obter a massa do queijo, procede-se à coagulação do leite, com o auxílio do coalho, que é um elemento fundamental na fabricação de queijos, onde este é composto de uma mistura de enzimas (quimiosina renina e pepsina bovina) e tem a função de precipitar a caseína, formando o coágulo firme, em tempo determinado, portanto a coagulação do leite corresponde à formação de um gel, a coalhada, obtido através de modificações físico-químicas das micelas de caseína (CAVALCANTE, 2004).

A forma de produzir o Queijo Serrano pouco se alterou ao longo do tempo, sendo que a única mudança significativa com relação aos ingredientes foi a utilização de coalho químico industrial em substituição ao estômago de tatus ("buchinho ou coalheira") ou ao estômago químico de ruminantes (abomaso), como bovinos e ovinos 
(KRONE; MENASCHE, 2007; RIES et al., 2012).

A adição de coalho é realizada a partir de uma diluição prévia, em volume menor, seguida de homogeneização do leite. Nos meses mais frios do ano, é necessário evitar o esfriamento excessivo do leite até a adição do coalho, sendo utilizado o aquecimento do leite (RIES et al., 2012), uma vez que a temperatura que permite uma boa ação enzimática do coalho e o crescimento da cultura lática encontra-se na faixa de 32 a $35^{\circ} \mathrm{C}$. Abaixo de $20^{\circ} \mathrm{C}$, a formação de gel é extremamente lenta e a $10^{\circ} \mathrm{C}$, ou menos, não há coagulação (CAVALCANTE, 2004).

Cada etapa no processamento de um alimento deve ser vista como uma possível fonte de contaminação, principalmente quando ocorre manipulação e adição de outros ingredientes. A diluição do coalho é uma destas etapas, na qual se deve conhecer e garantir a qualidade da água utilizada. De acordo com a legislação brasileira (BRASIL, 1952), o estabelecimento de produtos de origem animal destinados à alimentação humana deve apresentar boletim oficial de exame da água, garantindo os padrões de qualidade da mesma.

\subsection{Corte da coalhada e amassamento}

Após a coagulação do leite, inicia-se a importante e delicada etapa da dessoragem - conjunto de ações que ajudam a separar o soro da massa do queijo, definindo a umidade do produto (CAVALCANTE, 2009).

A dessoragem consiste na desidratação mais ou menos intensa do coágulo para obter uma pasta de consistência variável. Ao mesmo tempo em que se elimina água, elimina-se uma parte das substâncias que se encontram em suspensão, ou seja, os elementos do lactossoro. Fundamentalmente é a maior ou a menor quantidade de soro, que fica retida na coalhada, que determina as características das diversas variedades de queijo: dureza, textura, velocidade e intensidade da maturação. Por isso, a operação de dessoragem tem grande importância no processo de fabricação.

Com o corte da coalhada ocorre a primeira dessoragem. Nesta etapa do processamento pode ocorrer adição de água quente à massa, para auxiliar na retirada do soro. O amassamento da massa tem por finalidade a retirada do soro.

A coalhada é colocada em saco de pano fino para facilitar o escoamento do lactossoro e permitir o amassamento da coalhada. O queijo é, então, prensado, com o apoio de um sistema (tradicional) que utiliza pedras para promover a prensagem. À noite, as peças de queijo são viradas para que a prensagem tenha efeito uniforme. Somente no dia seguinte, pela manhã, o queijo estará pronto para ser maturado (MENEZES et al., 2010).

\subsection{Enformagem}

Após a dessoragem, a massa é colocada nas formas. Os queijos de formato redondo eram mais frequentes antigamente e as fôrmas ("cinchos") eram feitas de finas lâminas de madeira, retiradas do tronco de árvores. Seu diâmetro era ajustado conforme a quantidade de coalhada e fixado amarrando-se tiras de couro no seu entorno e, posteriormente, com arame ou pequenos ganchos. Os queijos pesavam cinco quilogramas ou mais e eram maturados nas propriedades por períodos superiores há três meses quando, então, eram transportados até as regiões consumidoras (KRONE; MENASCHE, 2007; RIES et al., 2012).

Atualmente, o formato predominante dos queijos é o retangular e o peso varia entre 1 e $3 \mathrm{~kg}$. As mudanças verificadas no peso e formato dos queijos se deve à preferência dos consumidores por comprar uma "peça" inteira de menor tamanho e, consequentemente, de menor custo, enquanto que o formato retangular facilitaria o corte, a utilização e a conservação do queijo depois de cortado (RIES et al., 2012).

As formas utilizadas na produção do QAS são, na maioria das unidades produtivas, de madeira. A troca por outros materiais, no entanto, encontra grande resistência entre os produtores que afirmam que materiais como inox e plástico modificam as características sensoriais dos queijos.

$\mathrm{O}$ uso de formas e barris de madeira tem sido difundido por gerações na produção de alimentos artesanais. Os defensores destes materiais partem do princípio que tais superfícies, por apresentarem estrutura porosa, permitem o desenvolvimento de biofilmes, comunidades de fungos filamentosos, leveduras e bactérias do ácido acético e lático (BAL), que seriam responsáveis pelas características peculiares de alimentos como cidras, vinhos, vinagres e de uma gama variada de queijos artesanais, garantindo sabores e odores característicos desses alimentos, assim como sua segurança. Pesquisas recentes demonstraram que a presença de BAL, em biofilmes, diminuiu a adesão de patógenos como Escherichia coli e $S$. aureus, principais indicadores de práticas de fabricação insatisfatórias em ambientes de produção 
de alimentos (FERREIRA; FERREIRA, 2011).

$\mathrm{Na}$ indústria de laticínios, a formação de biofilmes dentro da linha de produção eleva a carga microbiana e, muitas vezes, contamina com patógenos os alimentos devido ao eventual desprendimento de porções aderidas. Desta maneira, podem colocar em risco a saúde do consumidor, além de ocasionar prejuízos financeiros à indústria, em decorrência da diminuição da vida de prateleira dos produtos alimentícios (SANTOS, 2010).

Microorganismos como S.aureus, Salmonella sp. E Listeria monocitogenes, patógenos importantes em doenças transmitidas por alimentos, também podem formar biofilmes que se desprendem e contaminam alimentos.

A fim de diminuir os riscos de contaminação na produção de alimentos, o Regulamento Técnico sobre as Condições Higiênico-Sanitárias e de Boas Práticas de Fabricação para Estabelecimentos Elaboradores/Industrializadores de Alimentos determina que os recipientes que são reutilizados devem ser feitos de material que permita a limpeza e a desinfecção completas. Devendo ser evitado o uso de madeira e outros materiais que não se possa limpar e desinfetar adequadamente, a menos que não tenha certeza de seu emprego não será uma fonte de contaminação. Deverá ser evitado o uso de diferentes materiais com a finalidade de evitar corrosão por contato (BRASIL, 1997).

\subsection{Prensagem}

A prensagem é usada para determinar a completa separação do soro da massa, tornado esta, assim, mais ou menos sólida e resistente, com forma definida e bom aspecto comercial. Seu principal objetivo consiste em transformar as partículas de coalhada em uma massa compacta que facilite seu manejo (CAVALCANTE, 2009).

As prensas são feitas através de um sistema de alavancas, cujo peso é feito com pedras (AMBROSINI, 2007) que podem ou não estar envoltas (saco plástico), como forma de evitar contato do material poroso da pedra com o queijo.

\subsection{Maturação}

A elaboração de quase todos os queijos implica em uma etapa de maturação onde, por ação dos microrganismos e enzimas, são produzidas diversas modificações que dão lugar a diferentes variedades de queijo. Durante este tempo, produz-se a transformação bioquímica gradual dos componentes do queijo em muitos produtos mais solúveis. Neste processo desenvolve-se o aroma e têm lugar várias modificações na pasta. A degradação dos componentes orgânicos do queijo é produzida pela ação conjugada e variável das enzimas e da flora microbiana (CAVALCANTE, 2009).

A maturação dos QAS é realizada em local próprio ou não para este fim. Segundo Ries et al. (2012), apesar das condições de ambiente e de processo não serem as mais adequadas, em muitas das propriedades, o processo de maturação aos quais os queijos foram submetidos contribuiu significativamente para adequar os queijos aos parâmetros microbiológicos estabelecidos pelas normativas, para este tipo de queijo aos 65 dias de maturação.

O Ministério da Agricultura, Pecuária e Abastecimento (BRASIL, 2013), com a Instrução Normativa $\mathrm{N}^{\circ} 30$, permitiu a maturação por um período inferior a 60 dias para queijos artesanais produzidos a partir de leite cru desde que comprovada, por estudos técnico-científicos, que tal redução no período de maturação não comprometa a qualidade e a inocuidade do produto. A normativa restringe a permissão para queijarias situadas em região de indicação geográfica registrada ou tradicionalmente reconhecida e em propriedade certificada como livre ou controlada para tuberculose e brucelose.

As propriedades rurais onde estão localizadas as queijarias devem descrever e implementar: I - Programa de Controle de Mastite, com a realização de exames para detecção de mastite clínica e subclínica, incluindo análise do leite da propriedade em laboratório da Rede Brasileira da Qualidade do Leite - RBQL - para composição centesimal, Contagem de Células Somáticas e Contagem Bacteriana Total - CBT; II - Programa de Boas Práticas de Ordenha e de Fabricação, incluindo o controle dos operadores, controle de pragas e transporte adequado do produto até o entreposto; e III - cloração e controle de potabilidade da água utilizada nas atividades.

Diferentemente do passado, em função das facilidades de transporte, o queijo é comercializado atualmente entre 10 e 20 dias após a sua fabricação, sendo reduzido o número de produtores que se dedicam a sua maturação na propriedade (RIES et al., 2012). Na ausência de tratamento térmico, a maturação a partir da combinação de fatores físicos, químicos e microbiológicos, é considerada como uma forma de garantir a inocuidade e qualidade microbiológica de um queijo. 
Santos (2010), ao analisar a carga microbiológica durante a maturação de queijo artesanal preparado a partir de leite cru, constatou que o período de nove semanas não foi suficiente para que o produto fosse considerado seguro para o consumo humano.

A comercialização de queijos artesanais com maturação inferior a 60 dias, até então proibida, foi liberada a partir de 2013 pelo MAPA (BRASIL, 2013). No entanto, esta liberação vem precedida de estudos técnico-científicos que comprovem a inocuidade do produto em tempo menor de maturação. No sentido de buscar adequação às novas normativas, estudos vêm sendo realizados pelos produtores do Queijo Artesanal Serrano com o apoio da Emater/RS e Instituições de Ensino.

\subsection{Considerações sobre o processo produtivo}

Apenas no Rio Grande do Sul, estima-se em 1.500 o número de famílias produtoras desse queijo. Apesar de sua importância, a produção ocorre geralmente na informalidade, colocando tanto os produtores quanto os consumidores em situação de insegurança (RIES et al., 2012).

Ao verificar a qualidade microbiológica do Queijo Serrano, com diferentes períodos de maturação, Schneider (2009) verificou ausência de L. monocytogenes e Salmonella spp. e contagem de Staphylococcus coagulase positiva (SCP), de acordo com as recomendações da legislação, em todas as amostras. Entretanto 11\% dos queijos foram considerados impróprios para consumo humano por apresentarem elevada contagem de Coliformes Termotolerantes (104 UFC.g-1), indicador de falhas de higiene no processo produtivo. A contaminação por microrganismos do grupo coliformes pode acarretar alterações nas características sensoriais, como sabor ácido e estufamento devido à produção de gás. Estes defeitos podem causar a deterioração precoce do produto, diminuindo o seu tempo de vida útil.

Segundo Ries et al. (2012), na busca por um produto inócuo e seguro ao consumidor, em 2001 foi iniciado, sob coordenação da Emater-RS, um projeto que visa a qualificação do produto, a legalização do processo artesanal e a certificação do produto.

Uma das etapas deste projeto prevê a implantação de boas práticas que já demonstraram, em propriedades estudadas, melhora na qualidade do leite utilizado na produção do QAS após a implantação de Boas Práticas Agropecuárias no processo de ordenha (MATOS, 2013). As Boas Práticas Agropecuárias (BPA) buscam assegurar que o leite e os seus derivados sejam seguros e adequados para o uso a que se destinam. Dentre as medidas recomendadas se destacam: a sanidade animal e a higiene na ordenha; ordenha e armazenagem do leite sob condições higiênicas; equipamentos adequados e mantidos em boas condições para ordenha e armazenamento do leite (FAO, 2013).

Por outro lado, a questão das boas práticas de fabricação também deverá ser implementada, uma vez que tanto as fôrmas como a queijeira (local onde se prensa o queijo e se escorre o excesso de soro), as prateleiras de cura, as pás usadas para quebrar a coalhada e outros utensílios, foram e continuam sendo de madeira, na maioria das propriedades visitadas, o que contraria a legislação vigente, uma vez que apresentam superfície porosa, de difícil higienização e capaz de promover o desenvolvimento de comunidades microbianas. Entretanto, mais do que uma questão de uso pela tradição, existe também todo um conhecimento associado aos utensílios utilizados e que compõe uma parte do "saber-fazer" tradicional (RIES et al., 2012). Ferreira e Ferreira (2011) demonstraram que o biofilme formado nos utensílios de madeira, utilizados na fabricação de queijos, pelos microrganismos que se desenvolvem durante a fabricação desse produto, é importante para a determinação das características peculiares desses queijos e que podem mesmo atuar no controle de certos microrganismos indesejáveis, através da competição pelo alimento.

Considerando que a produção nos moldes historicamente vigentes vinha se dando de modo marginal, alheio aos aspectos legais e sanitários, os produtores de QAS têm investido em tecnificação e adequação da produção aos critérios legais.

\section{COMERCIALIZAÇÃO E SEGURANÇA ALI- MENTAR}

De acordo com Portela et al. (2002), a atividade de produção de leite para a produção de queijos, embora tenha determinado a permanência de muitas famílias no meio rural, tem apresentado momentos de descapitalização e estagnação. Embora de caráter familiar, é uma produção sazonal, de pequena escala e, muitas vezes, secundária na propriedade, o que poderia explicar a dificuldade dos pequenos produtores em enfrentar o mercado e melhorar a qualidade de seus produtos artesanais. A segurança alimen- 
tar abrange o aspecto quantitativo, abordando a disponibilidade de alimentos, e o qualitativo, focando, principalmente, a saúde do consumidor. Este princípio envolve todos os elos da cadeia produtiva de alimentos (GONÇALO, 2006).

Os queijos são, em geral, produtos muito manipulados e, por este motivo, passíveis de contaminação, especialmente de origem microbiológica. Estas condições podem ser agravadas, quando processados com leite cru, sem o emprego das boas práticas e tecnologia adequada, ou sem a observância do tempo mínimo de maturação. O consumo de produtos lácteos, no Brasil, vem crescendo e queijos, como o Minas Artesanal do Serro, são comumente utilizados em refeições e sanduíches (SOUZA et al. 2008). Além disso, queijos artesanais têm grande importância sócio-econômica no Brasil, em consequência de seu ambiente histórico e cultural.

Até hoje, o QAS é um dos principais produtos das fazendas serranas, representando, não raras vezes, mais da metade da renda agrícola bruta desses estabelecimentos rurais e a principal atividade na rotina diária das famílias (RIES et al., 2012). A renda obtida da comercialização do QAS contribui para a manutenção das despesas domésticas das famílias. Entretanto, o produto ainda tem caráter sazonal na maioria das propriedades, uma vez que nos meses de inverno, com a diminuição da produção de leite e destinação prioritária deste aos terneiros, há queda na produção dos queijos e diminuição da renda nas propriedades (EMATER-RS, 2006).

Dos 66 produtores de bovinos de corte, relacionados no município de Cambará do Sul, 40 são produtores habituais de queijo. Eles produzem em torno de $35.000 \mathrm{~kg}$ de QAS por ano, o qual é comercializado em, pelo menos, 20 pontos de venda da cidade. A distribuição do produto se dá de maneira informal e não se tem informação sobre o volume de queijo que é destinado a outras regiões.

O QAS é comercializado no município de origem e, muitas vezes, em outros municípios da região, através do comércio intermunicipal proporcionado pela facilidade de locomoção e situação geográfica. De acordo com Menezes et al. (2010), a comercialização se dá, principalmente, em mercados das cidades próximas ou de Caxias do Sul, cidade pólo da região. Muitos produtores contam com a figura do atravessador - ou intermediário - para escoar sua produção. Ide e Benedet (2001) comentam que a produção e comercialização de queijos artesanais no Brasil está relacionada, muitas vezes, à produção informal.
A aproximação entre produção e consumo tem sido pautada como elemento fundamental para a manutenção de laços de confiança entre produtores e consumidores. Quando se pensa em alimentos tradicionais, as práticas de julgamento e os conhecimentos necessários para escolha do produto parecem evoluir com a própria história de sua produção, de forma que os consumidores assumem importante papel na definição de qualidade dos mesmos (MENEZES et al., 2010). As BPFs abordam os procedimentos realizados pela indústria, quanto à higienização das instalações, equipamentos e utensílios; controle de pragas e vetores; segurança da água; saúde e hábitos higiênicos dos colaboradores; descrição das tecnologias empregadas na fabricação dos produtos; prevenção da contaminação cruzada; definição de responsabilidades e periodicidades; análises e padrões utilizados na seleção e no controle de qualidade de matérias-primas, ingredientes e produtos acabados; procedimentos de recall e de atendimento ao consumidor, dentre outros (TEODORO et al., 2007).

Os critérios de escolha dos consumidores de Queijo Serrano apontam que a legitimação de produtos tradicionais está associada a critérios e atributos de qualidade conferidos pelos atores que compõem a rede de produção e consumo desses queijos. Evidencia-se, desse modo, que, diferentemente de ferramentas formais de certificação - que requerem certa padronização e atendimento de regras, como as sanitárias, por exemplo -, os mecanismos de legitimação social envolvem não apenas o saber-fazer tradicional, mas também expectativas diversas, redes de sociabilidade, conhecimento e confiança entre produtores e consumidores e demais atores envolvidos (MENEZES et al., 2010).

A agroindústria familiar rural surge como uma alternativa na busca de novos nichos de mercados, utilizando-se da maior diversidade de produtos e da diferenciação dos produtos através da transformação dentro da propriedade. Sua implantação é considerada uma alternativa eficaz como política de Desenvolvimento Rural, mas, com todos os esforços, existem muitas limitações neste setor, principalmente da legislação sanitária. A construção dos mercados e das regras que os regem, mesmo com o cumprimento das normas legais, vem de dentro do processo e com a colaboração de todos os atores: produtores e consumidores (NICHELE e WAQUIL, 2011).

A certificação de indicação geográfica, que é desafio para os municípios da região, é fator decisivo para o reconhecimento do produto. 
Faz-se necessário melhorar o sistema de produção, sem prejudicar o sabor tradicional e o saber-fazer típico, para evitar a exclusão dos produtores da atividade e garantir a manutenção do sistema produtivo na região.

\section{CONCLUSÕES}

A garantia da qualidade e da inocuidade do Queijo Artesanal Serrano está atrelada ao atendimento das regras previstas em legislação quanto à sanidade animal (controle de brucelose e tuberculose), período de maturação dos queijos e ao adequado emprego das boas práticas de fabricação. $\mathrm{O}$ uso adequado da tecnologia de produção artesanal, de estrutura física compatível com os critérios sanitários e água de qualidade, bem como a regulamentação dos procedimentos de produção, permitirão a produção de produtos inócuos e seguros ao consumo humano.

\section{REFERÊNCIAS}

AMBROSINI, L.B. Sistema Agroalimentar do Queijo Serrano: estratégia de reprodução social dos pecuaristas familiares dos Campos de Cima da Serra - RS. 194 f. Dissertação (Mestrado em Desenvolvimento Rural) - Universidade Federal do Rio Grande do Sul, Porto Alegre, 2007.

AMBROSINI, L.B.; FILIPPI, E.E. Sistema Agroalimentar do Queijo Serrano: Estratégia de Reprodução Social dos Pecuaristas Familiares no Sul do Brasil. In: CONGRESSO INTERNACIONAL DE LA RED SIAL, 4, Mar del Plata (Argentina), 2008. Disponível em: <http://www6.ufrgs.br/pgdr/arquivos/586.pdf >. Acesso em: 23 ago. 2009.

BARDIN, L. Análise de Conteúdo. São Paulo: Edições 70, 2011.

BRASIL. Ministério da Agricultura, Pecuária e Abastecimento. Portaria ${ }^{\circ} 146$, de 07 de março de 1996. Aprova os Regulamentos Técnicos de Identidade e Qualidade dos Produtos Lácteos. Disponível em: $<$ http//www.agricultura.gov.br $>$. Acesso em: 23 ago. 2009.

BRASIL. Ministério da Agricultura. Decreto ${ }^{\circ}$ 30.691, de 29 de março de 1952. Aprova o Novo Regulamento da Inspeção Industrial e Sanitária de Produtos de Origem Animal. Disponível em:
< http://sistemasweb.agricultura.gov.br/sislegis/ action/detalhaAto.do?method=gravarAtoPDF\&tipo $=$ DEC\&numeroAto $=00030691 \&$ seqA to $=000 \&$ valor Ano $=1952 \&$ orgao $=$ NI $\&$ codTipo $=\&$ desItem $=\&$ desIt emFim=>. Acesso em: 20 ago. 2010.

BRASIL. Ministério da Agricultura, Pecuária e Abastecimento. Portaria $n^{\circ} 368$, de 4 de setembro de 1997. Padroniza os processos de elaboração dos produtos de origem animal.

BRASIL. Ministério da Agricultura e do Abastecimento. Instrução Normativa $n^{\circ} 57$ de 16 dezembro de 2011. Estabelece os critérios adicionais para elaboração de queijos artesanais.

BRASIL. Ministério da Agricultura, Pecuária e Abastecimento. Instrução Normativa $n^{\circ} 62$, de 29 de dezembro de 2011. Aprova o Regulamento Técnico de Produção, Identidade e Qualidade do Leite tipo A, Cru Refrigerado, Pasteurizado e o Regulamento Técnico da Coleta de Leite Cru Refrigerado e seu Transporte a Granel. Disponível em: <http://sistemasweb.agricultura.gov.br/sislegis/action/detalhaAto.do? method $=$ consultarLegislacaoFederal $>$. Acesso 10 fev. 2014.

BRASIL - Ministério da Agricultura Pecuária e Abastecimento. Instrução normativa $n^{\circ} 30$ de 7 agosto 2013. Disponível em: <http://sistemasweb. agricultura.gov.br/sislegis/action/detalhaAto.do?m ethod $=$ consultarLegislacaoFederal $>$. Acesso 10 nov. 2013.

BRITO, J.R.F.; BRITO, M.A.V.P.; VERNEQUE, R.S. Contagem bacteriana da superfície de tetas de vacas submetidas a diferentes processo de higienização, incluindo a ordenha manual com participação do bezerro para estimular a descida do leite. Ciência Rural, v.30, n.5, p.847-850, 2000.

CAVALCANTE, F.M. Produção de queijos gouda, gruyére, mussarela e prato. $11 \mathrm{f}$. Trabalho de conclusão de curso (Graduação em Engenharia de Alimentos) - Universidade Católica de Goiás, Goiânia, GO, 2009.

CARNEIRO FILHA, D.M.V.; DOMINGUES, P.F.; VAZ, A.K. Imunidade inata da glândula mamária bovina: resposta à infecção. Ciência Rural, v.39, n.6, p.1934-1943, 2009.

CERVO, A.L.; BERVIAN, P.A. Metodologia Científica. São Paulo: McGraw-Hill, 1983. 
CRUZ, F.T.; MENASCHE, R.; KRONE, E.E.; WAGNER, S.A. Queijo Artesanal Serrano dos Campos de Cima da Serra: o saber-fazer tradicional desafiando a qualidade. In: CONGRESSO INTERNACIONAL DE LA RED SIAL, 4, Mar del Plata (Argentina), 2008. Disponível em: <http://www6. ufrgs.br/pgdr/arquivos/664.pdf>. Acesso em: 23 ago. 2009.

FAO - Food and Agriculture Organization. Guia de boas práticas na pecuária de leite. Produção e Saúde Animal - Diretrizes. Roma: IDF, 2013. Disponível em: <http://www.fao.org/docrep/017/ba0027pt/ ba0027pt.pdf>. Acesso em: 10 out. 2013.

FERREIRA. E.G.; FEREIRA, C.L.L. Implicações da Madeira na Identidade e Segurança de Queijos Artesanais. Revista do Instituto de Laticínios Cândido Tostes, v.66, n.381, p.13-20, 2011.

FORSYTHE, S. J. Microbiologia da segurança dos alimentos. 2 ed. ARTMED. 2013

GIL, A.C. Métodos e técnicas de pesquisa social. 6. Ed. São Paulo: Atlas, 2008. 200p.

IDE, L.P.A.; BENEDET, H.D. Contribuição ao Conhecimento do Queijo Colonial Produzido na Região Serrana do Estado de Santa Catarina, Brasil. Ciência e Agrotecnologia, v.25, n.6, p.1351-1358, 2001.

KRONE, E.E.; MENASCHE, R. Agregados e mulheres, o "queijo de final de semana" e o valor do trabalho. Raízes, v.26, n.1 e 2, p.113-119, 2007.

KRONE, E.E. Identidade e cultura nos Campos de Cima da Serra (RS): práticas, saberes e modo de vida de pecuaristas familiares produtores de queijo serrano. 146 f. Dissertação (Mestrado em Desenvolvimento Rural) - Universidade Federal do Rio Grande do Sul, Porto Alegre, RS, 2009.

MATOS, L.M. Avaliação da aplicação de boas práticas agropecuárias (BPA) na ordenha sobre a qualidade do leite bovino, em propriedades produtoras de queijo artesanal serrano. $30 \mathrm{f}$. Trabalho de Conclusão de Curso (Graduação em Medicina Veterinária) - Universidade Federal do Rio Grande do Sul, Porto Alegre, RS, 2013.

MENEZES, S.S.M.; CRUZ, F.T.; MENASCHE, R. Queijo de Coalho e Queijo Artesanal Serrano: identidades de produtores e de consumidores associadas a atributos de qualidade. In: CONGRESO LATIONAMERICANO DE SOCIOLOGÍA RURAL, 8, Porto de Galinhas, 2010. Disponível em: < http:// www.ufrgs.br/pgdr/arquivos/754.pdf > . Acesso em: 01 nov. 2013.

MORAES, C.R. Qualidade bacteriológica de leite bovino de mistura, in natura e beneficiado, e detecção sorológica de Brucelose em rebanhos da Região Metropolitana de Porto Alegre. 78 f. Dissertação (Mestrado em Microbiologia Agrícola e do Ambiente) - Universidade federal do Rio Grande do Sul, Porto Alegre, RS-BR, 2005.

NICHELE, F.S.; WAQUIL, P.D. Agroindústria familiar rural, qualidade da produção artesanal e o enfoque da teoria das convenções. Ciência Rural, v.41, n.12, p.2230-2235, 2011.

PANKEY, J.W. Hygiene at milking time in the prevention of bovine mastitis. British Veterinary Journal, v.145, p.401- 409, 1989.

PEDRICO, A.; CASTRO, J.G.D.; SILVA, J.E.C.; MACHADO, L.A.R. Aspectos higiênico-sanitários na obtenção do leite no Assentamento Alegre, município de Araguaína, TO. Ciência Animal Brasileira, v.10, n.2, p.610-617, 2009.

PEREIRA, B.P. Caracterização do leite utilizado para a produção de queijo artesanal serrano no município de Cambará do Sul. $46 \mathrm{f}$. Dissertação (Mestrado em Ciências Veterinárias) - Universidade Federal do Rio Grande do Sul, Porto Alegre, RS, 2012.

PORTELA, J.N.; VIÉGAS, J.; NEUMANN, P.S.; NETO, B.S.; LAURENTINO, L.D. Análise econômica de sistemas de produção com bovinocultura de leite da Depressão Central do Rio Grande do Sul. Ciência Rural, v.32, n.5, p.855-861, 2002.

RIES, J.E.; LUZ, J.C.S.; WAGNER, S.A. Projeto de qualificação e certificação do queijo serrano produzido nos Campos de Cima da Serra do Rio Grande do Sul - relato parcial da experiência. Agronegócio e Desenvolvimento Rural Sustentável, v.5, n.1, p.10-19, 2012.

RIO GRANDE DO SUL Secretaria da Agricultura, Pecuária e Agronegócio. Portaria n 214, de 14 de dezembro de 2010. Regulamento técnico para fixação de identidade e qualidade do queijo artesanal serrano. Porto Alegre, RS. Dis- 
ponível em: <http://www.legisweb.com.br / legislacao $/$ ?legislacao $=573178>$. Acesso em: 10 out 2011.

RITTER, R.; SANTOS, D.; BERGMANN, G.P. Análise da qualidade microbiológica de queijo colonial, não pasteurizado, produzido e comercializado por pequenos produtores, no Rio Grande do Sul. Higiene Alimentar, v.15, n.87, p.51-55, 2001.

SANTOS, A. S. Queijo Minas artesanal da microrregião do Serro - MG: Efeito da sazonalidade sobre a microbiota do leite cru e comportamento microbiológico durante a maturação. $68 \mathrm{f}$. Dissertação (Mestrado em Zootecnia) - Universidade Federal dos Vales do Jequitinhonha e Mucuri, Diamantina, MG, 2010.

SCHNEIDER, R.N. Análise microbiológica e do sistema produtivo do queijo serrano produzido no município de Cambará do Sul/RS. 59 f. Trabalho de Conclusão de Curso (Graduação em Medicina Veterinária) - Universidade Federal do Rio Grande do Sul, Porto Alegre, RS, 2009.

ZAFFARI, C.B.; MELLO, J.F.; COSTA, M. Qualidade bacteriológica de queijos artesanais comercializados em estradas do litoral norte do Rio Grande do Sul, Brasil. Ciência Rural, v.37, n.3, p.862-867, 2007. 